\title{
Beyond the androgen receptor: the role of growth hormone secretagogues in the modern management of body composition in hypogonadal males
}

\author{
Deepankar K. Sinha ${ }^{1}$, Adithya Balasubramanian ${ }^{1}$, Alexander J. Tatem², Jorge Rivera-Mirabal ${ }^{3}$, Justin Yu ${ }^{1}$, \\ Jason Kovac ${ }^{2}$, Alexander W. Pastuszak ${ }^{4}$, Larry I. Lipshultz ${ }^{3,5}$ \\ ${ }^{1}$ Baylor College of Medicine, Houston, TX, USA; ${ }^{2}$ Men's Health Center, Urology of Indiana, Greenwood, IN, USA; ${ }^{3}$ Scott Department of Urology, \\ Baylor College of Medicine, Houston, TX, USA; ${ }^{4}$ Division of Urology, Department of Surgery, University of Utah School of Medicine, Salt Lake \\ City, UT, USA; ${ }^{5}$ Center for Reproductive Medicine, Baylor College of Medicine, Houston, TX, USA \\ Contributions: (I) Conception and design: All authors; (II) Administrative support: All authors; (III) Provision of study materials or patients: All \\ authors; (IV) Collection and assembly of data: All authors; (V) Data analysis and interpretation: All authors; (VI) Manuscript writing: All authors; (VII) \\ Final approval of manuscript: All authors. \\ Correspondence to: Larry I. Lipshultz, MD. Professor, Chief, Division of Male Reproductive Medicine and Surgery, Scott Department of Urology, \\ Baylor College of Medicine, 6624 Fannin Street, \#1700, Houston, TX 77030, USA. Email: larryl@bcm.edu.
}

\begin{abstract}
Male hypogonadism is an increasingly prevalent clinical condition that affects patients' quality of life and overall health. Obesity and metabolic syndrome can both cause and result from hypogonadism. Although testosterone remains the gold standard for hypogonadism management, its benefits are not always conserved across different populations, especially with regards to changes in body composition. Partially in response to this, growth hormone secretagogues (GHS) have emerged as a potential novel adjunctive therapy for some of the symptoms of hypogonadism, although current data on their clinical efficacy largely remain lacking. The present review examines the existing literature on the use of GHS and explores their potential complementary role in the management of hypogonadal and eugonadal males with metabolic syndrome or subclinical hypogonadism (SH). The GHS that will be discussed include sermorelin, growth hormone-releasing peptides (GHRP)-2, GHRP-6, ibutamoren, and ipamorelin. All are potent GH and IGF-1 stimulators that can significantly improve body composition while ameliorating specific hypogonadal symptoms including fat gain and muscular atrophy. However, a paucity of data examining the clinical effects of these compounds currently limits our understanding of GHS' role in the treatment of men with hypogonadism, but does open opportunities for future investigation.
\end{abstract}

Keywords: Growth hormone (GH); testosterone, secretagogues; androgens; hypogonadism; testosterone deficiency

Submitted Oct 04, 2019. Accepted for publication Nov 15, 2019.

doi: $10.21037 /$ tau. 2019.11 .30

View this article at: http://dx.doi.org/10.21037/tau.2019.11.30

\section{Introduction}

Testosterone is an essential hormone for male sexual, mental, and physical development in addition to ongoing health. Hypogonadism is a clinical syndrome that is characterized by low serum testosterone levels that are found in conjunction with clinical symptoms including decreased libido, reduced bone mass, increased fat mass, and a host of other metabolic disturbances $(1,2)$.

Male obesity is intrinsically linked to hypogonadism. Hypogonadal men are susceptible to more rapid fat accumulation which can lead to obesity. In turn, obese men are at an increased risk for hypogonadism given that adipose tissue contains aromatase which converts testosterone to estradiol. This conversion then leads to a hyper-estrogenic 
state that inhibits luteinizing (LH) secretion, undermining intrinsic testicular health and stifling testosterone production (3).

A number of studies have shown that hypogonadism occurs more commonly in men with hypertension, obesity, diabetes, or hypercholesterolemia, and that obese men are more than twice as likely to develop hypogonadism than their nonobese counterparts $(4,5)$. Conversely, men with low total and free testosterone levels are more likely to have metabolic syndrome with accompanying abdominal obesity and diabetes $(6,7)$. The initial physiologic changes that precede hypogonadism have been described as "subclinical hypogonadism" ( $\mathrm{SH})$, a metabolic condition in which gonadal dysfunction is present, but not yet clinically evident due to compensatory increases in LH or other detectable changes in the absence of clinical signs or symptoms (8). It has been postulated that early intervention in patients with $\mathrm{SH}$ may prevent the progression of this deleterious metabolic derangement.

Testosterone therapy (TTh) remains the gold standard treatment for hypogonadism. It can improve sexual function, reduce visceral fat, increase lean body mass, and improve bone health, among other benefits $(9,10)$. Although the positives of TTh are seen in most patients, emerging evidence suggests that the extent of these improvements may vary significantly between patient populations (11-13). In a recent meta-analysis of 16 trials of hypogonadal men receiving TTh, Guo et al. found that although TTh led to increased lean body mass and a reduction in total cholesterol levels, the observed decrease in fat mass was not significant. The authors also failed to observe changes in body weight, body mass index (BMI), or bone density (14). Cai et al. then conducted a separate meta-analysis examining 5 randomized control trials of hypogonadal men with type 2 diabetes receiving TTh. Though the men receiving TTh did demonstrate lower fasting glucose levels, and the breakdown between patients' fat loss and muscle gain was unclear, researchers failed to observe significant total body weight changes in comparison to the control groups (15). These findings highlight the fact that although TTh can improve lean body mass and other essential metabolic parameters, it may not inhibit fat mass increases that are seen with metabolic syndrome.

Growth hormone (GH) offers a method of treatment that can further address body composition independent of the androgen-dependent gonadal axis. GH therapy has been shown to improve lean body mass, decrease adiposity, and improve serum lipid profiles (16,17). In 2012, Hazem et al. conducted a meta-analysis of 54 randomized control trials of patients receiving GH therapy and found GH therapy to be associated with a significant reduction in adiposity and overall weight while potentiating increases in lean mass (18). Although these findings offer promise to hypogonadal men struggling with weight loss despite adequate TTh, GH therapy remains controversial and is tightly regulated. Side effects include joint stiffness, radiculopathy, edema, and a theoretical but never-demonstrated increased risk of malignancy. The 1988 and 1990 amendments to the Food, Drug and Cosmetic Act made it illegal to use GH in the United States for off-label conditions due to advertising that claimed GH can reverse the effects of aging. The widespread use of GH therapy as a performance-enhancing agent by multiple high-profile athletes further accelerated the implementation of these amendments (19).

As a result of these controversies and limitations, a new class of drugs known as growth hormone secretagogues (GHS) (Table 1) has emerged as a potential alternative to GH therapy. These compounds appear to possess many of the same beneficial effects as those seen with GH therapy itself while demonstrating none of the same adverse side effects or regulatory concerns. The GHS consist of a variety of synthetic peptide or non-peptide agents that stimulate endogenous GH release. This is achieved via direct growth hormone release hormone (GHRH) mimicry or through interactions with ghrelin/growth hormone secretagogue receptors (GHS-R) distinct from the classical hypothalamicpituitary-somatotropic axis (20). Studies have shown that treatment with GHS can similarly increase serum GH and IGF-1 levels up to those observed with recombinant GH therapy with comparable fat loss and lean mass gain. Notably, certain GHS can uniquely stimulate the physiologic pulsatile GH secretion observed in vivo; this in contrast to exogenous GH therapy which often leads to persistent supra-therapeutic serum levels of GH. Consequently, GHS administration has the potential to convey many of the same benefits traditionally associated with recombinant GH therapy with substantially less risk $(21,22)$. In this review, we examine the literature assessing the use of GHS to explore their potential as adjunctive or alternative therapies in hypogonadal males and men with $\mathrm{SH}$.

\section{Sermorelin}

Sermorelin [GHRH-(1-29)], is the "prototypical" GHS, as it is a GHRH analog derived from the first 29 amino acids of the GHRH protein (23). Sermorelin impacts the 
Table 1 Growth hormone secretagogues: key characteristics

\begin{tabular}{lllll}
\hline Growth hormone & Administration & Half-life & Known target receptors & Proposed clinical use \\
\hline Sermorelin & Subcutaneous & $10-20 \mathrm{~min}$ & GHRH receptor & Lean mass gain \\
GHRP-2 & Subcutaneous & $25-55 \mathrm{~min}$ & GHSR-1a & Lean mass gain, fat loss \\
& & & CD36 & Potent appetite stimulator \\
GHRP-6 & Subcutaneous & $2-3 \mathrm{~h}$ & GHSR-1a & Lean mass gain \\
Ibutamoren & Oral & & CD36 & Total weight gain \\
Ipamorelin & Subcutaneous & $1.5-2.5 \mathrm{~h}$ & GHSR-1a & \\
\hline
\end{tabular}

hypothalamic-pituitary-somatotropic axis, unlike other GHS which function via the ghrelin/GHS-R pathway. GHRH receptor activation leads to cAMP production via the $\mathrm{G}_{\mathrm{s}}$ protein/adenylate cyclase and mitogen-activated protein kinase pathways (24).

Sermorelin has been employed in both the diagnosis and treatment of GH deficiency although there is limited research on its use in the setting of hypogonadism (23). Gelander et al. evaluated the short-term effects of $1 \mathrm{mg}$ sermorelin and GHRH 1-40 injections on GH, IGF-1, prolactin, follicle-stimulating hormone (FSH), and $\mathrm{LH}$ levels in short children with pulsatile GH secretion (25). Participants were non-randomly allocated into 2 groups. One group was first treated with sermorelin followed by GHRH 1-40 with a one-week interval between treatments. The other group received both peptides in reverse order. It was noted that both peptides increased GH by a similar magnitude; however, sermorelin also produced small acute rises in prolactin, FSH, and LH. These findings revealed that sermorelin promotes changes in GH levels similar to those observed with endogenous GHRH. Simultaneously, sermorelin uniquely stimulated both FSH and LH release, implying a potential role in the treatment of hypogonadism via the stimulation of endogenous testosterone production. Consistent with this observation, in a later study examining GH-deficient rats, sermorelin therapy was shown to result in an increase in testosterone secretion (26).

Corpas et al. evaluated sermorelin's effects on GH and IGF-1 levels in 9 young men 22 to 33 years old and 10 elderly men 60 to 78 years old (27). All 10 elderly men were given 14 days of twice daily injections of either low $(0.5 \mathrm{mg})$ or high dose $(1 \mathrm{mg})$ sermorelin which was then held for 14 days before being restarted for another 14-day period. Measured outcomes included serum GH, IGF-1, IGFBP-3, and testosterone levels in addition to body weight, BMI, and waist-hip ratio. In the elderly men, high-dose sermorelin treatment elevated mean 24-h GH, peak GH amplitude, and GH area under the peaks. The older men had lower baseline IGF-1 levels when compared to the younger men but sermorelin treatment resulted in elevations in IGF-1 in a dose-response fashion to levels approaching those of the younger men. In addition, the elevations in IGF1 remained above baseline levels in the elderly men even 2 weeks after stopping sermorelin, suggesting that sermorelin can produce longer lasting effects. Compared to baseline, the mean peak GH secretory responses were significantly increased in elderly men at both low and high doses.

No significant correlations were observed between total body weight and sermorelin treatment, but the study did not account for concurrent fat loss and muscle gain. Consistent with this, patients' waist-hip ratio and GH peak following sermorelin actually showed an age-independent inverse correlation. Additionally, in elderly men, serum testosterone levels were positively correlated with 24-h mean GH levels although it should be noted that these improvements in testosterone were not statistically significant. The authors also observed that the areas under GH peaks at night were significantly higher than those during the day for both young and elderly men, confirming that the majority of GH release occurs at night irrespective of age. These findings highlight that sermorelin is an effective stimulator of $\mathrm{GH}$ and IGF-1 levels in elderly men with reduced IGF-1 levels.

Vittone et al. conducted a prospective study to analyze the effects of once nightly injections of sermorelin in healthy elderly men (28). A total of 11 men aged 64 to 76 years were given $2 \mathrm{mg}$ of subcutaneous sermorelin nightly for 6 weeks. Following this, GH, IGF-1, skeletal 
muscle function, body composition, and endocrinemetabolic functions were measured as outcomes. Sermorelin therapy almost doubled the 12-h mean amount of GH released, but no significant changes to mean peak amplitude and number of peaks were observed. Essentially, sermorelin was found to augment the duration of rhythmic GH release without pushing serum levels above physiologic norms. Analysis of the nocturnal GH production showed that this increase in GH release was limited to approximately $2 \mathrm{~h}$ after sermorelin administration. Interestingly, the authors observed that IGF-1 levels did not significantly increase at 2 or 6 weeks of nightly treatment, while the Corpas study showed significant increases in IGF-1 with twice daily treatment. This suggests that the timing and frequency of sermorelin treatment significantly affects IGF-1 levels, with a higher frequency of administration resulting in more significant IGF-1 increases. With regards to body composition, this study failed to observe any significant changes of body weight, BMI, waist-hip ratio, lean body mass, or percent total fat mass. Sermorelin did however lead to significant improvements in 2 of the 6 muscle strength tests and the abdominal crunch, a test of muscle endurance. However, as with the Corpas et al. study, no significant changes in testosterone levels were observed. Interestingly, a decrease in mean systolic blood pressure was observed as an effect of sermorelin treatment. These findings support the conclusion that sermorelin can stimulate GH and IGF-1 secretion, but that this is dependent both on the frequency of dosing and the timing of serum hormone measurement.

Similar to the study above, Khorram et al. conducted a single-blind randomized placebo-controlled trial to evaluate the effects of sermorelin in both elderly men and women but elected for an extended treatment duration of 5 months (29). Ten women and nine men between 55 and 71 years old were administered 4 weeks of nightly subcutaneous placebo followed by 16 weeks of $10 \mu \mathrm{g} / \mathrm{kg}$ of sermorelin. The outcomes measured included GH response, IGF-1, IGFBP-1, IGFBP-3, body composition, serum lipids, and metabolic effects. The authors observed that sermorelin led to significant increases in GH release for the $2 \mathrm{~h}$ after administration and the 12-h mean GH levels at both 4 week and 16 weeks of treatment compared to placebo for both genders. No changes were observed with GH pulse frequency or amplitude. Subsequently, levels of IGF-1, IGFBP-3, and GH binding proteins (GHBP) were each increased. IGF-1 levels rose significantly by 2 weeks of treatment and remained elevated until 12 weeks before declining at 16 weeks. No changes in body weight, body fat mass, or dietary intake were observed in either gender. However, in men, lean body mass was significantly increased by $1.26 \mathrm{~kg}$. In both genders, a significant increase in skin thickness was observed after 16 weeks. For men, no changes in testosterone levels were observed but a significant increase in insulin sensitivity was noted along with improvements in wellbeing and libido. These results highlight that, compared to the short-term treatment in the Vittone study, longer term treatment with sermorelin results in increases in GH and IGF-1 in addition to changes in body composition seen with increased lean body mass. Although body weight, body fat, and testosterone levels were unchanged, these findings demonstrate the potential for sermorelin as adjunctive or alternative therapy in hypogonadal men, and further highlight the need for additional long-term studies.

Sigalos et al. conducted a retrospective review assessing the effects of combined Growth hormone-releasing peptides (GHRP)-2, GHRP-6, and sermorelin therapy in 14 hypogonadal men on TTh (30). These men were given thrice daily $100 \mu \mathrm{g}$ doses of this combined GHS therapy via subcutaneous injection for an average period of 134 days following which IGF-1, T, FT, E, LH, and FSH were measured at follow-up intervals of 90, 180, and 270 days. The authors noted that GHS combination therapy led to significant increases in IGF-1 at all three follow-up timepoints. Subjects who were also treated with either an aromatase inhibitor or tamoxifen therapy for hyperestrogenemia or gynecomastia saw elevations in IGF-1, but these increases were less pronounced than those observed in men not receiving anti-estrogen therapy. However, the retrospective nature of the study, small sample size, and strict inclusion criteria limit a broader applicability of the findings. Additionally, the lack of comparator groups receiving GHS monotherapy and data regarding changes in body composition restrict the ability to fully understand the impact of the individual GHS. Despite these shortcomings, these findings highlight that sermorelin can lead to elevations in IGF-1 when used in conjunction with other GHS, showing the potential role of sermorelin in the treatment of hypogonadism.

The study's results also emphasize the role of sermorelin as a potent GH and IGF-1 stimulator, which can yield significant increases in lean body mass. Although rare adverse events such as nausea, facial flushing, and redness at the injection site were noted, sermorelin appears to have a very favorable safety profile. Future large, longitudinal studies are needed to better characterize sermorelin's 
potential complementary role in management of hypogonadal males and men with $\mathrm{SH}$.

\section{GHRP-2 \& GHRP-6}

GHRP are short synthetic amino acid sequences that trigger GH secretion. These non-natural peptides lead to GH secretion by interacting with receptors at both pituitary and hypothalamic sites. While the exact mechanism of action of GHRPs continues to be elucidated, prior work has shown that GHRPs bind to receptors that are distinct from those utilized by endogenous GHRH $(22,31)$. GHRPs interact with two different receptors: growth hormone secretagogue receptor 1a (GHSR-1a) and CD36. GHSR-1a, which is bound natively by ghrelin and sometimes called the "ghrelin receptor", is expressed primarily in the brain, including the anterior pituitary gland, hippocampus, and hypothalamic arcuate nucleus. It is also present in the pancreas islets, thyroid, and adrenal glands, adipose tissue, and the myocardium (32). CD-36 is expressed extensively within endothelial cells, immune cells, adipocytes, cardiac and skeletal muscle, hepatocytes, and several other regions (33). Activation of these two receptors affects several downstream signaling pathways, culminating in a host of antifibrotic, anabolic, vasodilative, cardioprotective, and antiinflammatory effects (34).

GHRP-6 was the first GHRP to be studied in humans and spurred the development of other analogs including GHRP-2 (35), which is a more potent stimulator of GH secretion than GHRP-6 (36,37). In contrast to GHRP-6, which induces an intracellular calcium response and protein kinase C activity, GHRP-2 stimulates cAMP production, mimicking the mechanism of action of endogenous GHRH. Additionally, in vitro studies employing bovine pituitary cell cultures have further confirmed that GHRP-2 and GHRP-6 modulate their effects via distinct receptors and signaling pathways $(38,39)$. These differences also manifest themselves clinically. For example, while both compounds can increase serum IGF-1 levels, GHRP-6 provokes a significant hunger response in patients, potentially indicating a distinct interaction with the ghrelin receptor.

GHRPs have been employed in various clinical settings, including in the management of hypogonadal men $(21,40)$. Veldhuis and colleagues evaluated the effects of GHRP on the waveform and timing of GH secretion in 12 eugonadal men and 10 men with experimentally induced hypogonadism (41). Ten men were given 2 injections of depot leuprolide acetate 3 weeks apart to create a hypogonadal state. The other 12 men were not given leuprolide and served as a control group. The secretagogue infusions were then started 10 to 18 days after the second leuprolide injection. A combined analysis found that the treatment with GHRP-2 led to a 47 -fold increase in pulsatile GH secretion, while GHRH treatment itself only led to a 20 -fold increase. Interestingly, combination of both GHRH and GHRP-2 led to a 54-fold increase in pulsatile GH secretion compared to controls. Moreover, GHS treatment decreased the time to maximal GH secretion with a median time reduction of $43 \%$. These findings demonstrate that GHRP-2 is a potent stimulator of GH secretion in both eugonadal and hypogonadal men with a synergistic effect when co-administered with GHRH, from which sermorelin is derived.

Veldhuis et al. conducted a prospective, randomized double blind trial to further evaluate the effects of GHRH and GHRP-2 in 24 healthy young men with experimentally induced hypogonadism (42). All 24 men were given 2 injections of depot leuprolide acetate three weeks apart, following which 13 men were given saline and 11 were given $200 \mathrm{mg}$ testosterone enanthate weekly for 3 doses. The study measured multiple serum hormone values throughout the treatment period while also assessing changes in the GH release waveform induced by GHRH $v s$. GHRP-2. The authors found that increased abdominal visceral fat (AVF) negatively affected GHRH's ability to induce GH release while increased serum IGF-1 levels actually facilitated GHRH's efficacy. In contrast, GHRP2 induction of GH was unaffected by either factor and still induced a greater 2-fold increase in pulsatile GH secretion compared to GHRH. This conserved efficacy despite AVF and existing serum IGF-1 levels being notable, as many hypogonadal men struggle with increased amounts of adiposity. Given that GHRH efficacy is reduced in men with elevated AVF, these results suggest that GHRP-2 may be both a potent $\mathrm{GH}$ stimulator and overall a better option for increasing GH levels in men with increased AVF and adiposity when compared to GHRH alone (and by proxy sermorelin) $(16,17)$.

In a follow-up study, Veldhuis and colleagues assessed the effects of age, IGF-1 levels and AVF on GHRH and GHRP treatment response in 25 healthy men (43). All 25 men, including 13 young men and 12 older men, received two depot leuprolide acetate injections three weeks apart to create an acutely hypogonadal state. The inclusion of older men in the study was significant because older men have lower levels of sex steroids at baseline compared to 
young men (44). The measured outcomes of the study included GH, estradiol, testosterone, IGF-1, IGFBP-1, and IGFBP-3 levels along with evaluation of basal and pulsatile GH secretion. GHRH treatment led to a 90- and a 50 -fold increase in peak GH concentration in young men and old men, respectively. GHRP-2 treatment led to a 181- and a 130-fold increase in peak GH concentration in young men and old men, respectively. Both GHRH and GHRP-2 treatment resulted in increased GH secretion in young men compared to older men. Overall, however, the effects of GHRP-2 were twice that of GHRH across both age groups. This finding highlighted that GHRP-2 leads to significantly higher GH secretion when compared to GHRH irrespective of age.

Once again, the authors evaluated various predictors of treatment response. In contrast with their prior work, AVF actually did negatively impact GHRP-2's efficacy at increasing serum GH levels this time. Moreover, IGF-1 levels were a positive predictor of GHRH and GHRP induced GH release. These conflicting results from the same investigators over the course of two separate studies underscore the fact that further work is required to understand the relationship between systemic factors and GHRP-2 treatment response. Despite limitations including small sample sizes, experimentally induced hypogonadism amongst otherwise healthy subjects, and a short period of evaluation, both studies by Veldhuis et al. speak to the importance of exploring the use of GHRP in hypogonadal men.

In the previously mentioned study by Sigalos et al., both GHRP-2 and GHRP-6 were administered with sermorelin as part of a combination GHS regimen (30). Although this approach limits our understanding of each individual compound, the increases in IGF-1 levels seen at 90, 180, and 270 days are a testament to the GHRP compounds' efficacy.

The above literature supports the notion that GHRPs are potent stimulators of GH and IGF-1 which can potentially confer several metabolic benefits, including potentiating fat loss. Further work should assess whether these associated benefits persist among larger, more diverse patient populations. Furthermore, additional research is required to characterize the impact of GHRPs across longer periods of time and among patients with chronic hypogonadism.

\section{Ibutamoren (MK-677)}

Ibutamoren, also known as MK-677, is a nonpeptide compound, derived using GHRP-6 and spiroindanylpiperidine (45). Like GHRPs, ibutamoren activates Ltype $\mathrm{Ca}^{2+}$ channels which leads to intracellular calcium increases and protein kinase $\mathrm{C}$ activation. Studies have demonstrated that ibutamoren and GHRP-6 function through the same receptor and that ibutamoren synergistically interacts with GHRH. Consequently, many patients receiving ibutamoren will report an increase in hunger similar to that seen with GHRP-6. Ibutamoren is uniquely attractive as, unlike other GHS that require subcutaneous administration, it displays excellent oral availability and a long halflife (21).

Although ibutamoren's specific utility in the treatment of hypogonadism has yet to be thoroughly studied, several publications have assessed ibutamoren's influence on GH release and body composition. Chapman et al. assessed ibutamoren's effects on serum levels of both GH and IGF1 in a randomized, double-blind placebo-controlled trial. A total of 32 healthy elderly subjects ( 15 women and 17 men) 64 to 81 years old were randomized into two groups of 16 (46). The first group received once daily dosing of either 2, 10, or $25 \mathrm{mg}$ of ibutamoren or placebo. The second group received a daily dose in both the morning and the evening with at least one of these doses being a placebo. Participants underwent 2 separate 14-day treatment periods which were separated by a 2 to 3 -week washout period. An additional 14 days of treatment followed the second treatment period. Measured outcomes included serum GH, IGF-1, cortisol, prolactin, IGFBP-1, IGFBP-3, T3, T4, TSH, and fasting glucose and insulin.

When compared to baseline, both 10 and $25 \mathrm{mg}$ ibutamoren doses increased the mean 24-h GH concentration by $57 \%$ and $97 \%$, respectively. These ibutamoren treatments boosted pulsatile GH release yielding a 1.7 -fold increase in $\mathrm{GH}$ secretion over $24 \mathrm{~h}$. For the $25 \mathrm{mg}$ dose, IGF-1 levels were also increased by $55 \%$ at 2 weeks and $88 \%$ by 4 weeks. The IGF-1 levels of all subjects rose to levels normal for young adults. Ibutamoren did not significantly impact cortisol levels but did elevate prolactin, fasting glucose and insulin levels. These findings confirmed that ibutamoren is a potent GH and IGF-1 stimulator for patients with lower baseline GH and IGF-1 levels $(47,48)$.

Svensson and colleagues conducted a prospective, double-blind RCT to evaluate ibutamoren's effect on body composition and energy expenditure (49). The trial included 24 men between 19 and 49 years old with a $\mathrm{BMI}>30 \mathrm{~kg} / \mathrm{m}^{2}$ and waist-hip ratios $>0.95$. These men were given either daily $25 \mathrm{mg}$ ibutamoren or placebo for 8 weeks. Assessed outcomes included GH, IGF-1, prolactin, cortisol, hydroxycorticosteroids, body weight, visceral fat, fat-free mass (FFM), basal metabolic rate (BMR), glucose, 
and insulin. Ibutamoren increased serum GH peak levels and area under the curve. The largest increase in these parameters was observed 2 weeks following treatment. Serum IGF-1 and IGFBP-3 were also significantly increased at 2 weeks post treatment. Paralleling the Chapman et al. study, ibutamoren led to an elevation in serum prolactin at 2 and 8 weeks but no significant changes were observed in serum or urine cortisol.

The ibutamoren treatment group experienced a significant weight gain of $2.7 \mathrm{~kg}$ at 8 weeks, which decreased to a nonsignificant $1.8 \mathrm{~kg}$ weight gain 1 week after the end of treatment. This change in weight was attributed to mild fluid retention that was noted with the ibutamoren treatment arm that resolved with treatment cessation. In addition, FFM significantly increased by $3 \mathrm{~kg}$ with ibutamoren treatment compared to placebo while there were no changes in total body fat. BMR was increased at 2 weeks of treatment with ibutamoren but there were no changes in daily caloric intake, fasting concentrations of free fatty acids, glycerol, or ketones compared to baseline or placebo. These findings once again showcased the GH-stimulatory effects of ibutamoren. Although there were no significant decreases in body fat, the increases in FFM indicated that ibutamoren has the potential to affect body fat levels with a possibly longer duration of higher dose treatment.

In a follow-up study, Svensson et al. used the same experimental design described above to investigate ibutamoren's effects on serum leptin, thyroid hormones, testosterone, and gonadotropin levels (50). While the authors found that total body fat was unchanged as previously observed, the mean total body fat decreased by a non-significant $0.2 \mathrm{~kg}$ at 2 weeks and $0.4 \mathrm{~kg}$ at 8 weeks compared to baseline. Additionally, serum leptin levels, which reflect the amount of total body fat, and leptin/body fat ratio were increased at 2 weeks of treatment despite there being no increases in body fat or appetite $(51,52)$. Increases in leptin and leptin/body fat ratio may promote earlier satiety and confer further benefit to patients seeking to alter their body composition. Ibutamoren also led to an increase in TSH and increases in serum T3 levels at 8 weeks. Ibutamoren treatment did not affect FSH and LH levels, but did lead to decreased total testosterone levels with conserved free testosterone levels. Despite small sample sizes and short evaluation periods, both studies by Svensson et al. showed the promise of exploring ibutamoren use in hypogonadal men and eugonadal men with SH.

Nass et al. conducted a 2-year randomized, double-blind, placebo-controlled, modified-crossover trial evaluating ibutamoren's effects on body composition (53). Sixty-five healthy men and women 60 to 81 years old were divided into a once daily $25 \mathrm{mg}$ ibutamoren treatment group ( $\mathrm{n}=43$ ) or a placebo group $(n=22)$ for the first year of the study, whereas during year two, the placebo group received $25 \mathrm{mg}$ ibutamoren. The original ibutamoren treatment group was separated into either a placebo or continued ibutamoren treatment group. Measured outcomes included GH, IGF1, lipids, cortisol, insulin sensitivity, body composition, physical function, and muscle strength.

During the first year, ibutamoren resulted in a significant 1.8 -fold increase in 24-h mean GH levels and a 1.5 fold increase in serum IGF-1 levels. Body composition increases in FFM, limb lean mass, and thigh muscle area were observed. At 12 months, a $0.14 \mathrm{mmol} / \mathrm{L}$ decrease in LDL cholesterol was observed with ibutamoren treatment, although no changes in total testosterone levels were observed. At two years, the changes observed during the first year with ibutamoren were sustained. The group that started ibutamoren during the second year saw the same changes while the group that switched to placebo in the second year saw a reversal of the changes induced by ibutamoren treatment in the first year. These findings demonstrate that ibutamoren treatment can increase GH and IGF-1 levels for up to 2 years.

While the literature above firmly supports ibutamoren as a potent GH and IGF-1 stimulator that can significantly impact body composition, these data remain limited by the trial settings of clinical and $\mathrm{SH}$ and emphasize the need for larger, longitudinal studies among more diverse populations.

\section{Ipamorelin}

Ipamorelin is a synthetic pentapeptide that is a selective agonist of the ghrelin/ GHS receptor pathway (54). By mimicking ghrelin, ipamorelin selectively binds the same GHSR-1a receptor as GHRP-2, GHRP-6, and ibutamoren $(55,56)$. This interaction with GHSR-1a leads to a GH release from the pituitary gland, which can influence a number of anabolic processes including appetite regulation, fat processing, and overall energy usage (57). As mentioned previously, the GHSR-1a receptor is also present in a number of regions outside the brain including the gastrointestinal tract (55). Several studies have evaluated ipamorelin's ability to improve gastric motility in the setting of postoperative ileus $(58,59)$. Greenwood-Van Meerveld et al. assessed ipamorelin's effects in rodent models with induced postoperative ileus (POI) (58). The authors 
observed that ipamorelin had a dose-dependent effect on improving gastric emptying and thereby reversed POIinduced delayed gastrointestinal transit compared to nonPOI controls.

Beck et al. evaluated ipamorelin's effects on POI in bowel resection patients via a multicenter, double-blinded, placebo-controlled trial (59). A total of 114 patients undergoing either open or laparoscopic bowel resection received either twice daily $0.03 \mathrm{mg} / \mathrm{kg}$ ipamorelin $(\mathrm{n}=56)$ or placebo treatment $(n=58)$ on POD 1 until POD 7 or discharge. Measured outcomes included time to first tolerated meal and first bowel movement. Although both these clinical endpoints did not reach statistical significance when comparing ipamorelin to placebo, data from this study did suggest that patients undergoing open laparotomy had shorter times to return of gastrointestinal function when compared to the broader literature (60).

Lall et al. conducted a 9-week study with female GHdeficient and GH-intact mice to assess ipamorelin's effects on adiposity and weight gain (61). Over the course of 9 weeks, GH-deficient mice and non-GH-deficient mice were injected twice daily with either $250 \mu \mathrm{g} / \mathrm{kg}$ ipamorelin, $1.75 \mathrm{mg} / \mathrm{kg}$ human $\mathrm{GH}$, or $0.9 \%$ saline. After 9 weeks, body weight in the GH-deficient mice increased by $15.3 \%$ in those treated with ipamorelin compared to $95.5 \%$ in those treated with GH. In non-GH-deficient mice, ipamorelin and GH led to $16.9 \%$ and $27.5 \%$ increases in body weight respectively. The timing of the weight gain differed between agents as ipamorelin only produced weight gain within the first 1-2 weeks whereas GH-treated mice saw weight gain consistently across the 9 weeks. It is worth noting, however, that there were no changes in the relative weight of the dissected organs with ipamorelin while GH led to increased liver weight. This suggests that patients treated with ipamorelin may not experience the same organomegaly as that seen in patients treated with GH itself.

Ipamorelin led to increases in the sum of the relative fat pad weights compared to the saline-treated controls while GH treatment led to a decrease. DEXA scans in GHintact mice revealed that ipamorelin increased total body fat percentages compared to saline-treated controls while GH had no effect. At 2 weeks, serum leptin levels were increased with ipamorelin compared to saline-treated controls and an increase in cumulative food intake during the first week. These findings highlight that ipamorelin functions independent of $\mathrm{GH}$ as it caused weight gain in both GHdeficient and GH-intact mice. Furthermore, ipamorelin has significant adipogenic effects and causes significant weight gains early in treatment that stabilizes over time.

Although limited work has explored ipamorelin's effects on hypogonadism specifically, the compound's interactions with the GI tract are an important factor in determining body fat and overall composition. The above literature therefore draws attention to ipamorelin as a potent and selective stimulator of GH that can significantly influence the GI system, body composition, and adiposity. Adverse effects associated with treatment were rare and similar to those reported with sermorelin. Further human studies evaluating ipamorelin's effects are required. Longitudinal studies are required to further assess the compound's adjunctive role in the treatment of hypogonadal and eugonadal patients.

\section{Conclusions}

Male hypogonadism is an increasingly prevalent clinical condition that can significantly impact patients' quality of life and overall health. Obesity and metabolic syndrome can both cause and result from hypogonadism, creating a "vicious cycle" from which patients struggle to escape. Although TTh remains the gold standard treatment for hypogonadism, its benefits are not uniform and demonstrate significant variability between different populations. The somatotropic axis presents a unique treatment opportunity to address issues with body composition observed in hypogonadal men. GH therapy can increase lean body mass and reduce adiposity. However, GH therapy itself is controversial, tightly regulated, and carries the risk of edema, joint stiffness, and radiculopathy. As such, treatment with GHS offers an exciting and novel alternative for clinicians. GHS increase serum levels of endogenous GH and IGF-1 in a similar fashion to what is observed with exogenous GH therapy while not exceeding physiologic norms. Sermorelin, GHRP-2, GHRP-6, ibutamoren, and ipamorelin each show potential for use in the management of body composition concerns associated with hypogonadism and metabolic syndrome, as either monotherapy or adjunct therapy in combination with TTh. All 5 of these GHS are potent stimulators of both GH and IGF-1 and can significantly improve overall body composition. However, with a lack of large longitudinal studies specifically examining the use of GHS in the management of hypogonadal men, our understanding of their role and any potential long-term risks is limited. Regardless, this knowledge gap presents a unique investigational opportunity that could significantly advance the management of hypogonadal men. 


\section{Acknowledgments}

Funding: AW Pastuszak is a National Institutes of Health (NIH) K08 Scholar supported by a Mentored Career Development Award (K08DK115835-01) from the National Institute of Diabetes and Digestive and Kidney Diseases. This work is also supported in part through a Urology Care Foundation Rising Stars in Urology Award (to AW Pastuszak). The content is solely the responsibility of the authors and does not necessarily represent the official views of the NIH.

\section{Footnote}

Provenance and Peer Review: This article was commissioned by the Guest Editors (Larry I. Lipshultz, Alexander W. Pastuszak) for the focused issue "Contemporary Issues and Controversies in Men's Health" published in Translational Andrology and Urology. The article was sent for external peer review organized by the Guest Editors and the editorial office.

Conflicts of Interest: The focused issue "Contemporary Issues and Controversies in Men's Health" was commissioned by the editorial office without any funding or sponsorship. LIL serves as an unpaid editorial board member of Translational Andrology and Urology from Nov 2019 to Oct 2021. LIL and AWP served as the unpaid Guest Editors of the focused issue. Dr. Pastuszak: Endo Pharmaceuticals-advisor, consultant, speaker, research support; Boston Scientificadvisor; Antares Pharmaceuticals_advisor; Bayer AGspeaker. Dr. Lipshultz: American Medical Systems (Speaker); AbbVie (Consultant); Lipocine (Consultant); Aytu Bioscience (Consultant); Endo Pharmaceuticals (Speaker/Consultant). The other authors have no conflicts of interest to declare.

Ethical Statement: The authors are accountable for all aspects of the work in ensuring that questions related to the accuracy or integrity of any part of the work are appropriately investigated and resolved.

Open Access Statement: This is an Open Access article distributed in accordance with the Creative Commons Attribution-NonCommercial-NoDerivs 4.0 International License (CC BY-NC-ND 4.0), which permits the noncommercial replication and distribution of the article with the strict proviso that no changes or edits are made and the original work is properly cited (including links to both the formal publication through the relevant DOI and the license). See: https://creativecommons.org/licenses/by-nc$\mathrm{nd} / 4.0 /$.

\section{References}

1. Rey RA, Grinspon RP, Gottlieb S, et al. Male hypogonadism: an extended classification based on a developmental, endocrine physiologybased approach. Andrology 2013;1:3-16.

2. Kumar P, Kumar N, Thakur DS, et al. Male hypogonadism: Symptoms and treatment. J Adv Pharm Technol Res 2010;1:297-301.

3. De Lorenzo A, Noce A, Moriconi E, et al. MOSH Syndrome (Male Obesity Secondary Hypogonadism): Clinical Assessment and Possible Therapeutic Approaches. Nutrients 2018. doi: 10.3390/nu10040474.

4. Mushannen T, Cortez P, Stanford FC, et al. Obesity and Hypogonadism-A Narrative Review Highlighting the Need for High-Quality Data in Adolescents. Child (Basel, Switzerland) 2019. doi: 10.3390/children6050063.

5. Mulligan T, Frick MF, Zuraw QC, et al. Prevalence of hypogonadism in males aged at least 45 years: the HIM study. Int J Clin Pract 2006;60:762-9.

6. Brand JS, Rovers MM, Yeap BB, et al. Testosterone, sex hormone-binding globulin and the metabolic syndrome in men: an individual participant data meta-analysis of observational studies. PLoS One 2014;9:e100409.

7. Corona G, Monami M, Rastrelli G, et al. Testosterone and metabolic syndrome: a meta-analysis study. J Sex Med 2011;8:272-83.

8. Giannetta E, Gianfrilli D, Barbagallo F, et al. Subclinical male hypogonadism. Best Pract Res Clin Endocrinol Metab 2012;26:539-50.

9. Saad F, Aversa A, Isidori AM, et al. Testosterone as potential effective therapy in treatment of obesity in men with testosterone deficiency: a review. Curr Diabetes Rev 2012;8:131-43.

10. Yassin A, Haider A, Haider KS, et al. Testosterone Therapy in Men With Hypogonadism Prevents Progression From Prediabetes to Type 2 Diabetes: Eight-Year Data From a Registry Study. Diabetes Care 2019;42:1104-11.

11. Traish AM. Testosterone and weight loss: the evidence. Curr Opin Endocrinol Diabetes Obes 2014;21:313-22.

12. Saad F, Haider A, Doros G, et al. Long-term treatment of hypogonadal men with testosterone produces substantial and sustained weight loss. Obesity (Silver Spring) 
2013;21:1975-81.

13. Haider A, Yassin A, Doros G, et al. Effects of long-term testosterone therapy on patients with "diabesity": results of observational studies of pooled analyses in obese hypogonadal men with type 2 diabetes. Int J Endocrinol 2014;2014:683515.

14. Guo C, Gu W, Liu M, et al. Efficacy and safety of testosterone replacement therapy in men with hypogonadism: A meta-analysis study of placebocontrolled trials. Exp Ther Med 2016;11:853-63.

15. Cai X, Tian Y, Wu T, et al. Metabolic effects of testosterone replacement therapy on hypogonadal men with type 2 diabetes mellitus: a systematic review and meta-analysis of randomized controlled trials. Asian J Androl 2014;16:146-52.

16. Rudman D, Feller AG, Nagraj HS, et al. Effects of human growth hormone in men over 60 years old. N Engl J Med 1990;323:1-6.

17. Reed ML, Merriam GR, Kargi AY. Adult growth hormone deficiency - benefits, side effects, and risks of growth hormone replacement. Front Endocrinol (Lausanne) 2013;4:64.

18. Hazem A, Elamin MB, Bancos I, et al. Body composition and quality of life in adults treated with GH therapy: a systematic review and meta-analysis. Eur J Endocrinol 2012;166:13-20.

19. Holt RIG, Erotokritou-Mulligan I, Sönksen PH. The history of doping and growth hormone abuse in sport. Growth Horm IGF Res 2009; 19:320-6.

20. Ghigo E, Arvat E, Camanni F. Orally active growth hormone secretagogues: state of the art and clinical perspectives. Ann Med 1998;30:159-68.

21. Sigalos JT, Pastuszak AW. The Safety and Efficacy of Growth Hormone Secretagogues. Sex Med Rev 2018;6:45-53.

22. Bowers CY. Growth hormone-releasing peptide (GHRP). Cell Mol Life Sci 1998;54:1316-29.

23. Prakash A, Goa KL. Sermorelin: a review of its use in the diagnosis and treatment of children with idiopathic growth hormone deficiency. BioDrugs 1999;12:139-57.

24. Pombo CM, Zalvide J, Gaylinn BD, et al. Growth hormone-releasing hormone stimulates mitogen-activated protein kinase. Endocrinology 2000;141:2113-9.

25. Gelander L, Lindstedt G, Selstam G, et al. Effects of acute intravenous injection of two growth hormone-releasing hormones (GHRH 1-40 and 1-29) on serum growth hormone and other pituitary hormones in short children with pulsatile growth hormone secretion. Horm Res 1989;31:213-20.
26. Chatelain PG, Sanchez P, Saez JM. Growth hormone and insulin-like growth factor I treatment increase testicular luteinizing hormone receptors and steroidogenic responsiveness of growth hormone deficient dwarf mice. Endocrinology 1991;128:1857-62.

27. Corpas E, Harman SM, Piñeyro MA, et al. Growth hormone (GH)-releasing hormone-(1-29) twice daily reverses the decreased $\mathrm{GH}$ and insulinlike growth factor-I levels in old men. J Clin Endocrinol Metab 1992;75:530-5.

28. Vittone J, Blackman MR, Busby-Whitehead J, et al. Effects of single nightly injections of growth hormonereleasing hormone (GHRH 1-29) in healthy elderly men. Metabolism 1997;46:89-96.

29. Khorram O, Laughlin GA, Yen SS. Endocrine and metabolic effects of long-term administration of [Nle27] growth hormone-releasing hormone-(1-29)-NH2 in age-advanced men and women. J Clin Endocrinol Metab 1997;82:1472-9.

30. Sigalos JT, Pastuszak AW, Allison A, et al. Growth Hormone Secretagogue Treatment in Hypogonadal Men Raises Serum Insulin-Like Growth Factor-1 Levels. Am J Mens Health 2017;11:1752-7.

31. Gondo RG, Aguiar-Oliveira MH, Hayashida CY, et al. Growth hormone-releasing peptide-2 stimulates $\mathrm{GH}$ secretion in GH-deficient patients with mutated GHreleasing hormone receptor. J Clin Endocrinol Metab 2001;86:3279-83.

32. Müller TD, Nogueiras R, Andermann ML, et al. Ghrelin. Mol Metab 2015;4:437-60.

33. Febbraio M, Silverstein RL. CD36: implications in cardiovascular disease. Int J Biochem Cell Biol 2007;39:2012-30.

34. Berlanga-Acosta J, Abreu-Cruz A, Herrera DG-DB, et al. Synthetic Growth Hormone-Releasing Peptides (GHRPs): A Historical Appraisal of the Evidences Supporting Their Cytoprotective Effects. Clin Med Insights Cardiol 2017;11:1179546817694558.

35. Arvat E, di Vito L, Maccagno B, et al. Effects of GHRP2 and hexarelin, two synthetic GH-releasing peptides, on GH, prolactin, ACTH and cortisol levels in man. Comparison with the effects of GHRH, TRH and hCRH. Peptides 1997;18:885-91.

36. Wu D, Chen C, Katoh K, et al. The effect of GH-releasing peptide-2 (GHRP-2 or KP 102) on GH secretion from primary cultured ovine pituitary cells can be abolished by a specific GH-releasing factor (GRF) receptor antagonist. J Endocrinol 1994;140:R9-13.

37. Thomas A, Kohler M, Mester J, et al. Identification of the growth-hormone-releasing peptide-2 (GHRP-2) in a 
nutritional supplement. Drug Test Anal 2010;2:144-8.

38. Camanni F, Ghigo E, Arvat E. Growth hormone-releasing peptides and their analogs. Front Neuroendocrinol 1998; 19:47-72.

39. Roh SG, He ML, Matsunaga N, et al. Mechanisms of action of growth hormone-releasing peptide- 2 in bovine pituitary cells. J Anim Sci 1997;75:2744-8.

40. Popovic V, Leal A, Micic D, et al. GH-releasing hormone and GH-releasing peptide-6 for diagnostic testing in GH-deficient adults. Lancet (London, England) 2000;356:1137-42.

41. Veldhuis JD, Keenan DM. Secretagogues govern GH secretory-burst waveform and mass in healthy eugonadal and short-term hypogonadal men. Eur J Endocrinol 2008;159:547-54.

42. Veldhuis JD, Keenan DM, Bailey JN, et al. Preservation of GHRH and GH-releasing peptide-2 efficacy in young men with experimentally induced hypogonadism. Eur J Endocrinol 2009;161:293-300.

43. Veldhuis JD, Keenan DM, Bailey JN, et al. Novel relationships of age, visceral adiposity, insulin-like growth factor (IGF)-I and IGF binding protein concentrations to growth hormone $(\mathrm{GH})$ releasing-hormone and $\mathrm{GH}$ releasing-peptide efficacies in men during experimental hypogonadal clamp. J Clin Endocrinol Metab 2009;94:2137-43.

44. Decaroli MC, Rochira V. Aging and sex hormones in males. Virulence 2017;8:545-70.

45. Smith RG. Development of growth hormone secretagogues. Endocr Rev 2005;26:346-60.

46. Chapman IM, Bach MA, Van Cauter E, et al. Stimulation of the growth hormone (GH)-insulin-like growth factor I axis by daily oral administration of a GH secretogogue (MK-677) in healthy elderly subjects. J Clin Endocrinol Metab 1996;81:4249-57.

47. Corpas E, Harman SM, Blackman MR. Human growth hormone and human aging. Endocr Rev 1993;14:20-39.

48. Sherlock M, Toogood AA. Aging and the growth hormone/insulin like growth factor-I axis. Pituitary 2007;10:189-203.

49. Svensson J, Lönn L, Jansson JO, et al. Two-month treatment of obese subjects with the oral growth hormone (GH) secretagogue MK-677 increases GH secretion, fatfree mass, and energy expenditure. J Clin Endocrinol Metab 1998;83:362-9.

50. Svensson J, Carlsson B, Carlsson LM, et al. Discrepancy between serum leptin values and total body fat in response to the oral growth hormone secretagogue MK-677. Clin
Endocrinol (Oxf) 1999;50:451-6.

51. Maffei M, Halaas J, Ravussin E, et al. Leptin levels in human and rodent: measurement of plasma leptin and ob RNA in obese and weight-reduced subjects. Nat Med 1995 Nov;1:1155-61.

52. Considine RV, Sinha MK, Heiman ML, et al. Serum immunoreactiveleptin concentrations in normal-weight and obese humans. N Engl J Med 1996;334:292-5.

53. Nass R, Pezzoli SS, Oliveri MC, et al. Effects of an oral ghrelin mimetic on body composition and clinical outcomes in healthy older adults: a randomized trial. Ann Intern Med 2008;149:601-11.

54. Raun K, Hansen BS, Johansen NL, et al. Ipamorelin, the first selective growth hormone secretagogue. Eur J Endocrinol 1998;139:552-61.

55. Kojima M, Kangawa K. Ghrelin: structure and function. Physiol Rev 2005;85:495-522.

56. Davenport AP, Bonner TI, Foord SM, et al. International Union of Pharmacology. LVI. Ghrelin receptor nomenclature, distribution, and function. Pharmacol Rev 2005;57:541-6.

57. Wren AM, Seal LJ, Cohen MA, et al. Ghrelin enhances appetite and increases food intake in humans. J Clin Endocrinol Metab 2001;86:5992.

58. Greenwood-Van Meerveld B, Tyler K, Mohammadi E, et al. Efficacy of ipamorelin, a ghrelin mimetic, on gastric dysmotility in a rodent model of postoperative ileus. J Exp Pharmacol 2012;4:149-55.

59. Beck DE, Sweeney WB, McCarter MD, et al. Prospective, randomized, controlled, proof-of-concept study of the Ghrelin mimetic ipamorelin for the management of postoperative ileus in bowel resection patients. Int $\mathrm{J}$ Colorectal Dis 2014;29:1527-34.

60. Delaney CP, Marcello PW, Sonoda T, et al. Gastrointestinal recovery after laparoscopic colectomy: results of a prospective, observational, multicenter study. Surg Endosc 2010;24:653-61.

61. Lall S, Tung LY, Ohlsson C, et al. Growth hormone (GH)independent stimulation of adiposity by GH secretagogues. Biochem Biophys Res Commun 2001;280:132-8.

Cite this article as: Sinha DK, Balasubramanian A, Tatem AJ, Rivera-Mirabal J, Yu J, Kovac J, Pastuszak AW, Lipshultz LI. Beyond the androgen receptor: the role of growth hormone secreta-gogues in the modern management of body composition in hypogonadal males. Transl Androl Urol 2020;9(Suppl 2):S149-S159. doi: 10.21037/tau.2019.11.30 